\title{
The Near-Death Experience: Private or Public?
}

\author{
Leon Rhodes \\ International Association for Near-Death Studies
}

ABSTRACT: This editorial contrasts the private, personal near-death experience with the public concept of the experience, and finds important messages for humanity that are common to both.

It would be difficult to think of an experience that is more private, secret, and personal than that brief, dramatic opening of nonphysical eyes to another realm of consciousness. Yet the near-death experience (NDE) is unquestionably of worldwide interest, affecting the human understanding of our existence, and changing fundamental beliefs about the meaning and purpose of life.

The existence of organizations to study and to make use of the neardeath experience raises the very pertinent question of how the private experience and the public perception of the NDE overlap. If we begin with the NDEs of individual humans, we are dealing with a phenomenon that is ineffable, as well as intimately personal in its effect on a particular individual at a particular moment in time. It is true that the popularization of the NDE resulting from Raymond Moody's bestseller and the subsequent books, articles, studies, television and radio shows, and public programs actually is based on these very short moments

Mr. Rhodes was Vice President of the International Association for Near-Death Studies, and editor of its newsletter, Revitalized Signs. Reprint requests should be addressed to Mr. Rhodes at Box 23, 2960 King Road, Bryn Athyn, PA 19009. 
that cannot be described, evaluated, or understood by anyone else. The accumulation of NDE accounts from countless individuals, however, has created a model of the near-death experience for humanity as a whole, with each experiencer having a few or perhaps many of the distinct elements including the out-of-body experience, the tunnel, the being of light, the beautiful realm, meeting departed loved ones, the life review, the "barrier," and the choice to return to unfinished obligations.

That is a sort of public NDE that belongs to all people, whether or not they have personally undergone the experience, and the two dominant results for the experiencer - the belief in a higher realm of consciousness and the loss of fear of death-are already being transmitted to a great many people who have not personally come to that verge of bodily death. But there are other consequences of the NDE for both the individual and the general public. Since it is likely that most of these have not yet been seriously studied, yet they are probably more important than the experience itself, it would be useful to consider the effects of the NDE on the experiencers and on their family and friends, and then try to evaluate the meaning of the NDE as a powerful and beneficial awakening to a new way of thinking for our times.

In a somewhat remote way we might compare the "discovery" of the NDE to the dawning of the realization that our world is a round globe, that the tiniest bits of matter are composed of countless molecules and atoms, that all around us are unseen, unfelt, and incredibly useful fields of energy only discovered within our century. Each of these, as well as other concepts now widely accepted, marked the beginning of a new understanding of our universe and ourselves.

Before I proceed, it is useful to note that the private versus public NDE question can be applied to the organizations devoted to exploring this fascinating subject. The private side of the NDE may include an experiencer's relationships with a very small number of persons, a spouse, good friend, or relative. It might include a trusted clergyman who seeks to reconcile the experience with the person's religious beliefs, and possibly a psychologist or doctor who can deal with the NDE from a professional background. It would include the sometimes difficult adjustments of the experiencer and his or her family.

The private aspects of the NDE may be encountered in a small "Friends of IANDS" chapter that meets regularly to allow experiencers to talk about their NDEs with other experiencers or others interested in the experience, or a support group to reassure and strengthen the experiencers or their spouses who are unable to deal with this amazing happening. Such relationships may not include much more than comparing the experiences, noting differences and similarities, or probing 
more deeply into the memory of the NDE and discussing its implications and consequences. Valuable friendships can come about and many "problems" ameliorated in the small group, networking, or counseling relationship.

These benefits, no matter how desirable, would not justify the sort of organization represented by the International Association for NearDeath Studies (IANDS). IANDS was organized in 1981 under the direction of Kenneth Ring to be primarily a research group of scientists and professionals such as doctors, psychiatrists, and psychologists committed to analysis of the NDE as reported by experiencers, using the scientific method. Researchers have attempted to both verify and give deeper understanding to experiences never before evaluated by scientists: a higher level of consciousness; a spiritual encounter with a very different world; a beautiful, loving existence in striking contrast to the conditions of a near-fatal injury, a lethal heart attack, or a deadly reaction of the physical body to some disorder.

This public aspect of the NDE suggests very different considerations. First of all, although it is compiled from the private accounts, it must be removed from the individual, except, perhaps, to classify experiencers into categories, so that even those fascinating details of the NDE become impersonal and almost abstract. What we identify as the public near-death experience should, as far as possible, apply to all experiencers, rather than to the 26-year-old mother of three with severe asthma problems, or to the salesman whose car plunged over an embankment on a rainy night.

This can in no way confine the NDE to a narrow event free from amazing and surprising exceptions. However infrequent these specific examples, the NDE must have parameters that include seeing a family pet, noticing that Uncle Jason now wears a robe in that beautiful realm, smelling Grandma's perfume, or dying children not having a "life review." It must include incredible variety yet somehow coalesce into a comprehensible universal NDE.

There are already so many books on the subject of the NDE that I find it easy to resist the temptation to write another, yet I have no doubt that large volumes could easily be written just to suggest the variety of the near-death experience. But there is a message when we consider the question of how the private NDE differs from the public concept of what happens at death. The private, personal NDE provides all the information needed for individual experiencers to reevaluate their lives, shift their perspectives, and recognize new values. From that amazing moment, they have a greater understanding of themselves. 
In a corresponding way, the public NDE, which never happened to any single individual, provides important guidelines to all those willing to recognize that the "crossing over" none of us can avoid is quite different from what has been supposed. What can we collectively learn from the public NDE? What is it that an organization like IANDS has to offer humanity at this point in time?

First of all, I would stress that we must not allow the NDE to be contaminated by a host of mystical experiences that are not part of the dying process. It is too easy to view the NDE as just another psychic or mystical event.

More important, we should recognize that the various elements of the NDE have some amazingly simple yet profound messages. Unquestionably, the universal public message (avoiding the so-called "negative" NDE) is that the dreaded moment of death is in all likelihood free of suffering, fright, or distress. Experiencers are astonishingly relaxed for the most part, accepting this unique adventure, though sometimes a bit bewildered. Awareness of this simple revelation by those who "have been there" should, in itself, be of tremendous significance to all of us.

Furthermore, the almost universal adjective used for the NDE is "loving," usually with "warm" included and even under dreadful situations, "pain-free" and "joyous." These simple ideas teach us much, especially that we are somehow loved, we are protected and, all appearances to the contrary, we are undergoing in dying an entirely normal procedure to advance our lives to a new level.

Surely a dominant feature of the NDE is the ineffable light. It is not a light to be confused with what we usually think of as light: daylight from the sun, spotlights, or something that hurts our eyes. Interestingly, it is contrasted to the familiar black, lightless tunnel. Would it be too presumptuous to suggest that we are here given a picture of a different kind of light, the light that illuminates the mind? And may the words "understanding" and "revelation" have something to do with this light and with that brilliant being greeting us? It seems somehow irreverent to ask who that being of light is. Identifications have been numerous: God, Jesus, Mary, an angel, my father, etc. Yet the quality of that being is consistently warm, wise, loving, kind, and reassuring. It is a guide, a helper, even when it tells us: "This is not your time."

What then is the message of that "realm" we enter? Experiencers struggle for words and settle for a few generalities, calling that realm "beautiful." What does this tell us? Think for a moment that we actually do not know why some things we see give us great pleasure. Other visions may be repulsive or of no significance, but the ability to 
see, to sense and to react to beauty is an incalculable blessing. No matter what the scene left behind-the wrecked car, the unattractive hospital room, the battlefield, or the squalor of our lives-this "beauty" is awaiting us. The plain fact that we will still be able to take great pleasure in what we will experience is quite different from the traditional concept of an afterlife in a kind of limbo and ethereal vagueness. The NDE tells us that there is beauty awaiting us, and that we will find it exciting, thrilling, delightful.

What of those people we encounter? "Departed friends and loved ones" that we recognize are there to welcome us, frequently in ways that reveal to us things we could not have known. No need to go into the details; we are entering a realm that is full of loved ones. Do we need to know more? They calmly recognize us and make us feel at home. They convey ideas to us without the cumbersome mechanics of vocalization. Ideas tell us far more than words could possibly convey. Almost effortlessly we find that time and space are of no importance and that we are able to enter into a new kind of existence. May we not look forward with pleasure to an existence in which our ideas are not distorted by the limitations of language?

Two other elements of the NDE are worth considering: the life review and the "barrier" or "choice"-that is, the turning point when we elect to return. Vividly described life reviews are commonly reported but never adequately described, so instead of being concerned with the details of that panoramic, full-color, three-dimensional reliving of our lives, we can be content with the simple message that all that we have done, felt, thought, or even imagined stays with us. We will still be the person who has lived, loved, and learned in this physical world. Our years of existence are not wiped away but go with us to provide the building blocks for our future personality and relationships with others.

I conclude this essay with an attempt to evaluate the frequently reported awareness of a dividing line, be it a border, fence, wall, stream, invisible barrier, gate, door, or a being obstructing our passage. We go no further, but return to our bodies. Without understanding it further, cannot we accept the implication that this life is important, that we do have obligations and unfinished responsibilities? This is a public message for all of us, whether experiencers or not. It is not a private matter but a clue to how we are to live our lives and prepare for whatever is beyond. 